\title{
What Determines \\ the Formal Versus \\ Relational Nature \\ of Local Government \\ Contracting?
}

Urban Affairs Review

48(3) 322-353

(C) The Author(s) 2012

Reprints and permission:

sagepub.com/journalsPermissions.nav

DOI: 10.1 I77/I0780874| |4324|8

http://uar.sagepub.com

๑SAGE

\section{Meeyoung Lamothe' and Scott Lamothe'}

\begin{abstract}
In this article, we examine the governance structures used to manage local service delivery contracts with an eye toward two specific concerns. First, we contend that public managers likely use dual regimes in which contract writing is more formal in nature than is the management style adopted during contract implementation. We also explore the determinants of such mechanisms. We find some evidence to support our contention in that managers frequently contact and communicate with their vendors despite the presence of clearly and formally written contracts. We further find that the formal versus relational nature of written contract features is influenced by different factors (service characteristics, market conditions, vendor ownership) than is management style (reputation, management capacity, expectations of continuing relationships).
\end{abstract}

\section{Keywords}

contracting, relational contracting, formal contracting, governance, local service delivery

\footnotetext{
'University of Oklahoma, Norman, OK, USA
}

\section{Corresponding Author:}

Meeyoung Lamothe, The University of Oklahoma, Department of Political Science, 455 W. Lindsey, Room 205, Norman, OK 73019-200I

Email: mlamothe@ou.edu 
In the local government contracting literature, two of the most common questions have been why do jurisdictions contract for services (the make-or-buy decision) (e.g., Ferris and Graddy 1986; Greene 1996; Hefetz and Warner 2004; Kodrzycki 1998) and, when they contract, what determines whether they choose to go with for-profit, nonprofit, or other government vendors (sector choice) (e.g., Brown and Potoski 2003a; Ferris and Graddy 1986; Lamothe, Lamothe, and Feiock 2008; Levin and Tadelis 2010; Stein 1993). Recently, however, as interorganizational resource exchanges become a prevalent practice in both the private and public sectors, scholars' interests have shifted from simply choosing between hierarchy-or-market prototype governance modes toward exploring the nature of the relationships among exchange partners and different management strategies emerging from their interactions. Notably, scholars conceptualize two contrasting governance regimes regulating interorganizational relations: formal and relational governance (Adler 2001; Hill 1990; Poppo and Zenger 2002; Uzzi 1997). Formal governance, as the name implies, relies heavily on detailed, formalized contracts that explicitly lay out expectations and sanctions. Relational governance, on the other hand, is looser and depends more heavily on norms of cooperation to ensure task completion and to protect the property rights of participants.

While there has been a tendency in the literature to dichotomize the relational versus formal governance question as an "either/or" proposition (Amirkhanyan 2009), more recently, scholars have begun to identify and theorize about a variety of mixed governance models that go beyond this bifurcation. Some directly test whether formal and relational governance methods function as mutually enhancing rather than competing mechanisms for different types of services (Goo et al. 2009; Poppo and Zenger 2002; Vandaele et al. 2007). Others point out that formal and relational management practices may coexist (Van Slyke 2007). For example, in her study of performance measurement, Amirkhanyan $(2009,546)$ finds that "joint decision making [a form of collaboration associated with relational governance] may in fact validate and enhance the existing [i.e., formal] contract monitoring procedures."

The goal of this study is to add to this literature by exploring the determinants of governance mode with an eye toward two specific concerns. First we present evidence, in-line with the contentions of scholars such as Van Slyke (2007) and Amirkhanyan (2009), that how contracts are written and how they are managed might vary in ways that indicate the coexistence of formal and relational mechanisms. Second, we examine what determines the extent of such regimes. While many studies have theorized as to why formal or 
relational governance may be preferable or, to a lesser extent, have examined the prevalence of such modes, few have empirically examined the determinants of these structures. Our study starts to fill this lacuna. In doing both, we rely on an original survey conducted by the authors that gathers information on how local governments manage their contracted services.

The remainder of the article is laid out as follows: We begin our inquiry by examining the two contrasting governance patterns (formal vs. relational) recognized in the literature, to include a discussion of the literature supporting the idea of the coexistence of these regimes, as well as why such coexistence makes sense in light of the obligations of government. Next, we explore factors that could affect how and when differing forms of governance might be chosen, keeping in mind that the effect of the factors might vary depending on whether we are talking about contract writing or management style. We then review the data gathering, research design, and techniques used in our analyses. This is followed by a discussion of the findings and their implications. Finally, we close with avenues for future research and concluding comments.

\section{Literature on Governance: Dichotomous or Mixed?}

As mentioned, the two distinctive patterns to describe (or prescribe) interorganizational resource exchanges are formal and relational governance (Poppo and Zenger 2002; Vandaele et al. 2007). Formal governance relies heavily on "detailed, binding legal agreements that specify the obligations and roles of both parties in the relationship" (Vandaele et al. 2007, 240). Such contracts are typically written with "highly specific deliverable output in a tightly specified time frame" (Sclar 2000,101) and explicitly lay out the sanction mechanisms that may be used straightforwardly if one party does not fulfill its commitments (Macneil 1978). The primary purpose of formal contracts is to protect the rights and properties of potentially opportunistic participants. As such, altruistic behavior is not expected and aggrieved participants utilize third-party remedies, such as courts, to resolve problems (Ring and Van de Ven 1992). Formal contracts are, at their extremes, characterized as "sharp in/sharp out" and resemble spot markets in that there is no expectation of an ongoing association among the participants of such transactions, given the assumption of the ample presence of potential suppliers and buyers in the market (Macneil 1978).

Relational contracts or, more broadly, relational governance since not all resource exchanges take contractual forms in these types of relationships are, 
on the other hand, less rigid than their formal counterparts, with the key components being flexibility, cooperation, and information sharing (Poppo and Zenger 2002). Maintenance of the relationship, as opposed to simple dispute resolution, is a primary concern; hence legal, third-party remedies are not preferred (Carson, Madhok, and $\mathrm{Wu}$ 2006). Rather, there is an expectation of ongoing communication and coordination over the lives of such contracts. When problems occur, as they are expected to (Macneil 1978), they are dealt with in ways that focus on salvaging and continuing the relationships and the partners are expected to be adaptable (Beinecke and DeFillippi 1999). One of the major reasons for the focus on cooperation and maintenance of the relationship is that the parties to such contracts often see themselves as essentially dependent upon one another (Sclar 2000). Taken to the extreme, relational contracts resemble "clans" in which individual and group goals are in close alignment (Ouchi 1980). We summarize the core attributes of formal and relational governance structures that we extract from the literature in Table 1.

The bifurcated view of governance discussed above implicitly supposes that formal and relational structures are somewhat mutually exclusive. From this perspective, formal and relational governance are thought of as substitutes in that informal agreements between exchange partners based on trust and reputation can supplant the detailed legal maneuvers involved in formal contract negotiation (Adler 2001; Gulati 1995; Larson 1992). Some researchers draw a more explicit contrast and assume a hostile relationship between formal and relational varieties of governance by arguing that strict adherence to formal control may hinder trust-building processes and thus work against relational governance (Ghoshal and Moran 1996) and increase opportunism (Bernheim and Whinston 1998).

In their well-cited study, Poppo and Zenger (2002) challenge the mutual exclusion thesis and argue complementary roles of formal and relational governances. According to their contention, formal contracts do not discourage relational governance. Rather, clear and specific contracts, in conjunction with commitments to ongoing associations promote cooperation among exchange partners by reducing risk. Formal structure is argued to be especially useful in the early stages of exchange where mutual trust based on repeated and continuous performance has yet to be built. Goo et al. (2009) confirm Poppo and Zenger's position (i.e., complements rather than substitutes) as they find that well-developed service-level agreements in formal contracts are positively associated with relational governance attributes such as harmonious conflict resolution and an emphasis on mutually beneficial relationships. 
Table I. Summary of the Characteristics of Formal and Relational Governance Modes

\begin{tabular}{|c|c|c|}
\hline \multirow[b]{2}{*}{ Attributes } & \multicolumn{2}{|c|}{ Governance Mode } \\
\hline & $\begin{array}{l}\text { Formal (classical, contractual, } \\
\text { complete) governance }\end{array}$ & Relational governance \\
\hline $\begin{array}{l}\text { Perspectives about relations } \\
\text { with vendors(Beinecke and } \\
\text { DeFillippi I999; Macneil } \\
\text { I978; Ouchi 1980; Ring } \\
\text { and Van de Ven I992, Sclar } \\
\text { 2000) }\end{array}$ & $\begin{array}{l}\text { - Anticipate short-term } \\
\text { relationship; } \\
\text { - Low risk/low trust; } \\
\text { - No expectation for } \\
\text { altruistic behavior. }\end{array}$ & $\begin{array}{l}\text { - Anticipate long-term } \\
\text { relationship, seek out } \\
\text { trustworthy partners; } \\
\text { - High risk/high trust; } \\
\text { - Expect altruistic behavior } \\
\text { in the interest of the } \\
\text { whole;Mutual dependency. }\end{array}$ \\
\hline $\begin{array}{l}\text { Market assumptions } \\
\text { (Beinecke and DeFillippi } \\
\text { 1999) }\end{array}$ & - Many vendors available. & - Few potential vendors. \\
\hline $\begin{array}{l}\text { Contract writing(Beinecke } \\
\text { and DeFillippi I999; Lee } \\
\text { and Cavusgil 2006; Macneil } \\
\text { 1978; Poppo and Zenger } \\
\text { 2002) }\end{array}$ & $\begin{array}{l}\text { - Detailed specification of } \\
\text { benefits, burdens, rules, } \\
\text { and rights; } \\
\text { - Monitoring for } \\
\text { compliance; } \\
\text { - Reliance on legal } \\
\text { remedies;Sharp in/sharp } \\
\text { out. }\end{array}$ & $\begin{array}{l}\text { - Comparatively ambiguous } \\
\text { contracts with anticipation } \\
\text { of adapting to changing } \\
\text { circumstances; } \\
\text { - Social norms serve } \\
\text { as principal mechanisms of } \\
\text { mediation or control; } \\
\text { - Aversion to third-party, } \\
\text { legal remedies. }\end{array}$ \\
\hline $\begin{array}{l}\text { Management style(Macneil } \\
\text { 1978; Ouchi 1980; Poppo } \\
\text { and Zenger 2002;Vandaele } \\
\text { et al. 2007; Van Slyke 2007) }\end{array}$ & $\begin{array}{l}\text { - Sanctions imposed as } \\
\text { written; } \\
\text { - Low levels of contacts } \\
\text { and coordination; } \\
\text { - Compliance a key } \\
\text { concern. }\end{array}$ & $\begin{array}{l}\text { - Sanctions and } \\
\text { remedies not imposed } \\
\text { but rather negotiated and } \\
\text { mediated; } \\
\text { - Flexibility, } \\
\text { solidarity, information } \\
\text { sharing. } \\
\text { - Maintenance of } \\
\text { relationship a primary } \\
\text { concern. }\end{array}$ \\
\hline $\begin{array}{l}\text { Service characteristics } \\
\quad \text { (Brown and Potoski 2003a; } \\
\text { Williamson 1985, 199I) }\end{array}$ & $\begin{array}{l}\text { Easy to define service } \\
\text { tasks; } \\
\text { - Easy to evaluate } \\
\text { service quality and } \\
\text { vendor performance; } \\
\text { - Tasks do not require } \\
\text { special investment or } \\
\text { customization and } \\
\text { involve standardized } \\
\text { service production } \\
\text { processes-incumbents } \\
\text { not advantaged. }\end{array}$ & $\begin{array}{l}\text { - Ambiguity in defining } \\
\text { service tasks; } \\
\text { - Difficult to assess } \\
\text { service quality and vendor } \\
\text { performance; } \\
\text { - Vendors are required to } \\
\text { make special investment to } \\
\text { satisfy buyers' customized } \\
\text { needs-incumbents } \\
\text { advantaged. }\end{array}$ \\
\hline
\end{tabular}


While the studies mentioned above are from the private sector, nondichotomous understandings and characterizations of governance emerge in the public administration and public management literatures as well, although the explicit testing of such models has not been as intensive. In their study of Kansas social service privatization experiments, for example, Romzek and Johnston (2002) find that well-planned and prepared contracts as well as ongoing "negotiation and collaboration among contracting partners" (p. 423) are necessary conditions for effective contract implementation. Likewise, Van Slyke (2007) reports that New York state and county government managers often use both formal and informal contract management and monitoring tools to steer their social service vendors. More specifically, the governments in his study adopt a variety of formal oversight mechanisms such as financial auditing, quality assurance, and monitoring site visits in their contracts, but they also actively engage in informal control activities involving frequent contact, feedback, information sharing, and communication with service providers and are slow to invoke formal sanctions when noncompliance or nonperformance occurs. Similarly, Amirkhanyan (2009) observes the common practice of joint decision making between local governments and their vendors in developing performance measures by which contractors are evaluated and concludes that her findings call into question the utility of dichotomizing governance patterns along the formal-relational spectrum.

The above discussion leads us to believe that public managers may adopt both formal and relational attributes in governing their contracts. Specifically, it seems plausible that contracting governments might write their contracts in ways that differ from how they actually manage them. As DeHoog (1990) points out, because of accountability concerns, government officials tasked with oversight functions may prefer formal controls, while those tasked with program management often desire flexibility. Hence, the expectation is that dual regimes may be in place in which written documents that conform to the precepts of formal governance are augmented with relational management practices.

\section{What Determines Governance Patterns?}

In general, we expect that the extent of formality in written contract features and management style are both shaped by various service, vendor, and jurisdictional characteristics. However, some of these factors might have different effects on structuring written contract terms as opposed to managing vendors once contracts are in place. 


\section{The Determinants of Written Contract Features}

Examining contract features centers around the degree of clarity and legality built into contract terms and conditions. For example, how clearly and specifically are service tasks, performance measures, and sanction clauses laid out in contract documents? How frequently is open bidding required as a formal contract term to enforce market discipline? We suspect that conventional arguments regarding service characteristics, vendor traits, and jurisdictional factors play significant roles in determining public managers' ability and willingness to pursue formalness.

Service characteristics. In the contracting literature, the nature of services has been a key variable in explaining local governments' decisions on governance (Brown and Potoski 2003a; Domberger and Jensen 1997; Ferris and Graddy 1986; Stein 1993). While the early literature recognizes various service characteristics in this regard (e.g., economies of scale, vendor availability, ease of monitoring; see for example, Ferris and Graddy 1986), Williamson's (1985) measurability and asset specificity dimensions based on the transaction costs economics (TCE) framework are used most extensively to classify services (Brown and Potoski 2003a, 2005; Ferris and Graddy 1991; Hirsch 1991; Lamothe, Lamothe, and Feiock 2008). Measurability has to do with how easy or difficult it is to describe exactly what tasks are to be undertaken and to measure and gauge performance. Asset specificity relates to specialized knowledge or resources that are required for service delivery or which may accumulate over the term of a contract and advantage the incumbent in subsequent procurement rounds. As challenges regarding measurability and/or concerns regarding asset specificity increase, the transaction costs to write, manage, and monitor contracts are amplified (see Williamson 1985). Low transaction services are often termed "hard services," while high transaction costs services are described as "soft services" (Amirkhanyan 2009; DeHoog 1990; Marvel and Marvel 2009; Sclar 2000).

This understanding of hard versus soft services, based on their transaction costs characteristics, has long served as a basis for the "discriminating alignment hypothesis" (Vandaele et al. 2007, 239) in governance study, positing that different production arrangements should be used for services with different levels of transaction costs to tap into the potential for efficiency gains (Brown and Potoski 2003a; Williamson 1985, 1991). Similar arguments have been made regarding the question of whether formal or relational contracting is more appropriate. Specifically, hard services are said to be best suited for formal contracting because of their fitness to clearly structured contracting environments and competitive market conditions (Vandaele et al. 2007). As 
such, contracts for hard services should explicitly lay out service tasks and sanctions while contracts for soft services should use flexible language that allows for ex post adjustments to handle the ambiguous and uncertain nature of service tasks. In sum, we expect that as the nature of services moves from hard to soft, the features of written contracts will move from formal to relational.

Vendor characteristics. Vendor traits such as ownership and reputation are also argued to affect governance decisions (Brown and Potoski 2003a; Hefetz and Warner 2004; Lamothe, Lamothe, and Feiock 2008; Van Slyke 2007). The common underlying factor determining where contracts fall on the formal-relational spectrum in this instance is the extent to which contractors are perceived as trustworthy. Trust is considered a core component of relational contracting (Poppo and Zenger 2002); therefore, trusted vendors should tend to be governed more relationally, all else held constant. Nonprofits are generally seen as more trustworthy than their profit-seeking business counterparts because of their nondistributive nature and purported goal alignment in the delivery of public services (Frumkin 2002; Hansmann 1987; Jang 2006; Salamon 1995; Smith and Lipsky 1993; Weisbrod 1977). Historically, public agencies tend to view nonprofits as partners in delivery more so than generic, replaceable vendors (Sclar 2000). In addition, nonprofits see themselves more as stewards of the public interest than contract agents looking for opportunities to promote their own interests (Van Slyke 2007). The literature is not as enlightening regarding other government vendors. However, it is conceivable that they are seen in manners similar to nonprofits or perceived to be even more trustworthy since they share the same institutional characteristics.

Independent from ownership, vendor reputation may also signify trustworthiness to contracting governments who then may use such information as a tool to control vendor opportunism, mitigating the need for highly formal control (Jensen and Meckling 1976). This is because reputation is a valuable commodity that helps firms retain business (Milgrom and Roberts 1988) and vendors can be expected to regulate their own behavior, even when they are not being watched, to avoid tarnishing an asset they have worked hard to develop.

Related to the above discussion is whether resource exchange participants generally foresee a continuing relationship or not. Expectations of continuity, regardless of their source (i.e., forced upon the partners by market conditions or because the participants see constancy as mutually beneficial), have been posited to impact the nature of the partnership. Borrowing from game theory, 
scholars such as Poppo, Zhou, and Ryu (2008) argue that cheating can be mitigated if firms anticipate an ongoing relationship in which continued cooperation has a higher payoff than short-term opportunism (see Axelrod 1984 for an exposition of how cooperation can be expected to develop). In such instances, some of the ex ante costs associated with formalizing contracts might be avoided because it is presumed that the vendor will not likely take advantage of the contracting government, since doing so is counterproductive in the long run. Similarly in the public management literature, Milward and Provan (2000,372), in discussing the commonness of ongoing relationships in social service contracting, state that "stability promotes a belief that cooperation will have a reasonable payoff." Consequently, contractors have less incentive to act against the interests of their principals when continuity is anticipated. When vendors are seen as potentially long-term partners in service delivery, relational patterns may prevail in contract writing.

Jurisdictional factors. In addition to transaction costs and vendor characteristics, it seems likely that the attributes of jurisdictions also play a role in formally structuring contracts. For example, Brown and Potoski (2003b, 156) posit that "council-manager governments are more likely to invest in contract management capacity than those governed under alternative arrangements." While they focus on whether jurisdictions do such things as conduct privatization feasibility studies or perform citizen satisfaction surveys, their logic would seem to extend to whether locales have the resources and expertise necessary to write exacting requests for proposals and contracts, as required under formal contracting regimes. Hence the expectation is that councilmanager governments tend to develop more formal contracts.

Another jurisdictional trait that might be influential is metro status. As Honadle $(2001,82)$ points out, urban jurisdictions may tend to have higher levels of internal capacity and, even when this is not the case, the overall capacity of rural governments may be diminished because they "do not have ... complementary institutions in the community" to augment their capacity. This lack of capacity could make it challenging for rural locales to undertake the tasks associated with formal governance. For example, Mohr, Deller, and Halstead (2010) find that rural jurisdictions less frequently utilize competitive bidding processes, which are, in many ways, a key component of formal contracting. Hence, contract writing in rural communities should be less formal than it is in higher capacity urban areas. The literature is not overly instructive regarding how suburban jurisdictions should compare with urban governments. However, extending the logic regarding rural governments 
explicated above, it seems reasonable to expect that the suburban-urban relationship will mirror the rural-urban relationship although the magnitude of the differences should be mitigated.

The final jurisdictional factor to discuss is the market environment. Regardless of service characteristics, vendor ownership, or jurisdictional capacities, we expect less formal contract writing in areas with weak vendor markets. This is a specific application of the more general argument that market conditions are associated with governance modes in a rather straightforward way - when markets are robust, formal contracting is indicated, when they are weak, relational contracting is expected to be more efficacious (Beinecke and DeFillippi 1999; DeHoog 1990; Sclar 2000). The logic is that competitive markets serve to allow for arms-length, sharp-in/sharp-out contracting since replacing vendors is easy and cheap. There is no need to expend scarce resources on building relationships because market discipline effectively constrains vendor opportunism. While rural areas might tend to have weak markets across the board, even large jurisdictions may suffer such problems on a service-by-service basis. Whenever thin markets are encountered, more relational forms of governance are expected.

\section{The Determinants of Management Style}

As mentioned previously, we expect management style to be more flexible and collaborative (i.e., more relational) than what contract features indicate as public managers may see needs to adapt to changing environments after contract terms are formally codified. Generally, we predict that many of these adjustments will fall within the broad boundaries set by formal contract structures and are influenced by the same factors shaping written contracts. That is, hard service contracts with clear language regarding contractors' obligations and sanction clauses enable, and to a degree compel, public managers to be more faithful to the legal structures they create. On the other hand, the ambiguity characterizing soft service contracts may force managers to become more relational in nature to allow for the flexibility and adjustment, which, in many ways, will simply be a necessity. Similarly, when there are anticipations of continuing relationships or few vendors in the market, more relational management styles are predicted. These expectations are heavily driven by the idea of dependence. If the contracting government feels the provider would be very difficult to replace, regardless of whether it is because they perceive them as partners or they are simply "stuck" because of market conditions, maintenance of the relationship may be of paramount 
importance. Formal, arms-length styles of managing contracts under such circumstances would seem inappropriate.

Divergence is expected when hypothesizing how ownership and jurisdictional characteristics affect public managers' management style, as compared to contract writing. Previously we posited that well-trusted vendors should be governed under more relational styles. We adhere to this assertion when considering such factors as reputation and nonprofit status of vendors that are indicative of trustworthiness. When other governments are contractors, however, the traits these types of vendors share with nonprofit contractors (e.g., nonditributive nature, goal congruence) might not necessarily lead to what appear to be relational management practices, especially in terms of how commonly public managers coordinate and communicate with vendors in implementing outsourced services. Recent empirical findings suggest that public managers tend to treat other government contractors differently from private for-profit as well as nonprofit vendors in that they display significant degrees of deference and institutional trust toward their fellow government vendors (Lamothe and Lamothe 2010). This intimate sharing of identity may result in a completely "hands-off" approach rather than frequent contacts and coordination in managing contracts.

Lastly, regarding jurisdictional characteristics, we argue that locales with high capacity, as might be revealed by the presence of professional managers and metro status, should be more likely to communicate with vendors during implementation but less likely to exercise discretion when issuing sanctions. We expect the reverse for low capacity locales. The logic is straightforward-high capacity indicates the existence of resources that can be deployed to efforts at information sharing and coordination, which may increase the probability of successful contracting, making such activity desirable. On the other hand, when capacity is low, public managers lack the resources for "hands-on" management and thus should participate in less coordination. This diverges from dichotomous expectations on governance in that high capacity, in this instance, is expected to lead to relational rather than formal management styles, despite the potential presence of formally written contracts. However, we do not expect high capacity will increase the use of discretion in sanctioning since, as we argue above, professionalized governments should tend to write more explicit contracts that unambiguously lay out vendor expectations, performance measures, and sanction procedures. When transgressions occur, both sides are aware of the procedures and consequences, mitigating the need for costly negotiations and thus reducing rather than increasing the use of discretion in sanctioning. Meanwhile, less 
professionalized government with low capacity are less likely to have written highly formalized contracts; thus, when problems are encountered, they will necessarily have to be more willing to negotiate settlements as sanctioning terms and mechanisms are not fully developed. Taken together, the above arguments lead us to posit that professionally managed locales should exercise sanction clauses as written, but engage in more contacts and coordination (because they can). Conversely, rural and suburban jurisdictions should engage in less communication but exercise more discretion when imposing sanctions.

\section{Data Collection}

We purchased a contact list from the International City/County Managers Association (ICMA), which maintains a database containing contact information for approximately 10,300 municipalities and counties in the United States. ICMA's list contains 1,519 governmental units with populations of 50,000 or greater (660 cities and 859 counties). It also contains 8,751 jurisdictions with populations less than 50,000. While most jurisdictions provide hard services, such as solid waste collection, fewer municipalities and counties provide soft services, such as health and human services. Since we posit that service characteristics play an important role in governance choice, we felt it best to limit our sample to larger jurisdictions that would be more likely to provide a wider array of services through a variety of arrangements (Levin and Tadelis 2010). We requested 2,000 contacts - all jurisdictions of 50,000 or greater and a random sampling of those ranging from 25,000 to 49,999 . Surveys were sent to each unit in our sample during the week of January 20, 2010. Reminder post cards were sent on February 10, 2010. During the week of February 24, the survey package was sent out again to all nonresponding jurisdictions in the hopes of receiving additional responses.

Each jurisdiction was asked to choose two services it delivers through contractual arrangements, one from a list of hard services and one from a list of soft services (see Appendix A for the lists), and answer a series of questions about the selected services and their related governance characteristics (Appendix B contains a catalog of the survey questions asked and how they relate to the variables used in the analysis). We use ICMA's classifications of public works/transportation and health and human services to define our hard and soft services, respectively. Most variables are measured on 5-point scales presenting opposing statements at each end of the formal-relational spectrum. ${ }^{1}$ The statements on the left, or low end of the scale, represent answers that should, by theory, be associated with formal governance and those on the 
right, or high end, with the purported expectations of relational contracting practices. Each case represents a jurisdiction's response for a given servicea government-service pair.

In the end we received responses from 359 jurisdictions, for a response rate of $18.0 \%{ }^{2}$ Of the responding jurisdictions, 69 indicate they do not contract for either type of service and 17 include no suitable information. In addition, some cases were missing data on variables relevant to our analyses. Because of these limitations, the number of jurisdictions included in our models range from 250 to 253 , depending on the variables associated with the models. Since we ask for information on two services, the maximum number of cases theoretically possible runs from 500 to 506, depending on the analysis. However, many jurisdictions only reported information for one service (most commonly the hard service), usually indicating they do not contract for the other type. So, in the end, the number of cases that could potentially be included in our analyses is 345 (with a total of 223 hard and 122 soft service cases), with actual $N$ s running from 339 to 345, depending, again, on the model.

As with any sample, there are questions as to the representativeness of our data. Turning to Appendix C, we see that our data set vastly oversamples jurisdictions with larger populations. As mentioned above, this was by design. However, it still has implications for the generalizability of this study. Our data are dominated by jurisdictions in the 50,000 to 249,999 population range, which are not representative of the overall distribution of local governments in the country. Thus, our findings are more relevant to medium to large locales. Our findings may not translate well to small jurisdictions (especially those with populations less than 10,000). We also undersample north-central and oversample western jurisdictions. It is not clear what, if any, implications there are for interpreting our results, but readers should be aware of this concern. Finally, council-manager forms of government are also overrepresented. This could make it challenging to find relationships between form of government and governance modes, since we have limited variation on this variable. It could also call into question how generalizable our findings are to other forms of government. ${ }^{3}$

\section{Measurement of the Dependent Variables}

To examine governance patterns, we collect five variables, three that tap into the characteristics of written contract documents and two that focus on management styles. All are 5-point scales, where the high end represents answers that point to relational governance (please see Appendix B for a more detailed 
review of how the dependent variables used in the analysis are coded). The three contract feature variables ascertain if contracts are rebid regularly, regardless of incumbent performance; if the contract explicitly spells out deliverables, performance measures, and reporting requirements; and whether the contract includes sanction clauses that specify detailed penalties. Enumerated rebidding schedules force the government to go back to the market periodically, which is important in imposing market disciplinesimply doing a good job is not enough to shield the vendor from possible replacement. Unambiguous language regarding vendor performance expectations, in combination with clear explication of sanctioning triggers and mechanisms, serve to plainly and legalistically define the government-vendor relationship. Contracts that have these characteristics are formal in nature. As contracts deviate from such configurations, they move toward the relational end of the continuum.

The management style variables define the frequency of contacts and coordination with the vendor during contract implementation and if sanctions are imposed as written in the contract with little discretion or negotiation. Frequent contacts and communication during contract implementation imply a willingness to share information, jointly solve problems, and coordinate actions. They are also indicative of a generally more "hands-on" management style. Hesitance to mechanistically impose sanctions when transgressions occur implies a preference to maintain relationships over a legalistic focus on protecting property rights. As such, high levels of contacts during contract execution and exercising discretion when imposing sanctions are hallmarks of relational governance.

Factor-analyzing dependent variables. If singular governance mechanisms are in place, the five variables discussed above should correlate positively. For example, if the contract features point to formal mechanisms (e.g., explicit task definitions and sanction mechanisms), then the management style variables should also (e.g., limited contacts and coordination and ready application of sanctions). In other words, all the variables should code toward the low end of the spectrum. The reverse, of course, would be expected if relational attributes are identified. However, if as we posit, both formal and relational modes coexist, the contract features and management style variables should not track well together.

To test this proposition, we entered the five variables into a principal components factor analysis. As the results in Table 2 show, the model produces two, rather than a single, factor. The three contract features variables (i.e., Frequency of rebidding, Contract specificity regarding deliverables, and 
Table 2. Principal Components Factor Analysis of Governance Structure Variables

\begin{tabular}{lcr}
\hline Variable & Factor I & Factor 2 \\
\hline Contract features & & \\
$\quad$ Frequency of rebidding & 0.704 & -0.006 \\
$\quad$ Contract specificity regarding deliverables & 0.828 & -0.034 \\
$\quad$ Contract specificity regarding sanction clauses & 0.872 & -0.078 \\
Management style & & 0.191 \\
$\quad$ Contacts and coordination & 0.539 & 0.502 \\
$\quad$ Use of discretion in sanctioning & 2.268 & 1.061 \\
Eigenvalue & 45.36 & 21.21 \\
Percent variance explained & \multicolumn{2}{c}{$66.57 \%$} \\
Total variance explained & \multicolumn{2}{c}{338} \\
$N$ & & \\
\hline
\end{tabular}

Contract specificity regarding sanction clauses) all load nicely on the first factor, indicating they are tapping into a single dimension that defines how contracts are written. Contacts and coordination loads negatively and weakly on the first factor, but strongly on the second factor, signaling that it is capturing a different facet of the governance structure - an aspect of how contracts are actually managed during implementation. Things are a bit more complicated for Use of discretion in sanctioning. It loads moderately well, and at nearly the same magnitude, on both factors, indicating it does not really "belong" to either. We interpret these results as evidence for the coexistence of formal and relational governance structures.

Based on the results of the factor analysis, we construct three dependent variables for use in the next part of our analysis - an examination of the determinants of governance structures. The first, Contract features, is an additive scale computed by summing the scores for the three component variables (thus the variable ranges from 3 to 15). The second and third dependent variables capture components of management style and are simply the Contacts and coordination and Use of discretion in sanctioning measures; hence these variables each range from 1 to 5 . We choose to go with the above variable constructions, rather than with factor scores, because Use of discretion in sanctioning is conceptually different than the variables making up Contract features and it does not obviously, from an empirical perspective, belong to either factor, so maintaining it on its own allows us to explore if the different measures have unique determinants. 


\section{Independent Variables, Control Variables, and Models}

The independent variables of interest used in the analysis include transaction cost service characteristics, vendor traits, and jurisdictional factors as described in the "What Determines Governance Patterns?" section. Readers are directed to Appendix B for detailed discussions of how the variables are constructed. In addition, while we posit that how contracts are written and how they are managed might diverge, it is likely that contract terms, in and of themselves, are influential, at least to some extent, in determining management patterns; hence this variable needs to be accounted for in our management style models. In many ways, this is mostly a control variable, but it also serves as a further test of our thesis regarding the coexistence of formal and relational governance mechanisms. Strong positive relationships with our management style dependent variables would tend to refute our claims (especially if very few or no other independent variables prove to be significant), whereas insignificant or negative coefficients would strengthen them.

Finally, we include three control variables, not previously discussed. Political connections defines the level of political connections the vendor has. While it is not obvious that such connections should lead to specific types of governance, it does seem probable that well-connected vendors might be treated differently in some way owing to the fact that they can call on their political benefactors to protect their interests if they run into problems in delivering services. As such, controlling for this property seems prudent. We also account for the type of government and the size of the jurisdiction. County identifies county, as opposed to municipal, governments. Finally, Population measures jurisdictions' populations in millions. Please see Table 3 for a presentation of the descriptive statistics for all of the variables included in the analysis.

Since Contract features is an additive scale that runs from 3 to 15 , we use ordinary least squares to estimate this model. On the other hand, both Contacts and coordination and Use of discretion in sanctioning are 5-point ordered variables, so we use ordered logit to run these models. ${ }^{4}$ As we posit the same independent variables are at play in determining each of the dependent measures, this leads to the following general model specifications:

Contract features/Contacts and coordination/Use of discretion in sanctioning $=\mathrm{b}_{1}$ Service measurability $+\mathrm{b}_{2}$ Asset specificity +

$\mathrm{b}_{3}$ Nonprofit $+\mathrm{b}_{4}$ Other government $+\mathrm{b}_{5}$ Reputation +

$\mathrm{b}_{6}$ Expectation of continuity $+\mathrm{b}_{7}$ Professional administrator $+\mathrm{b}_{8}$ Rural + 
Table 3. Descriptive Statistics for All Variables

\begin{tabular}{lcccc}
\hline Variable & Minimum & Maximum & Mean & Standard Deviation \\
\hline Contract features & 3 & 15 & $7.56 \mathrm{I}$ & 3.484 \\
Contacts and coordination & $\mathrm{I}$ & 5 & 3.953 & $1.09 \mathrm{I}$ \\
Discretion in sanctioning & $\mathrm{I}$ & 5 & 3.127 & 1.158 \\
Measurability & 2 & $\mathrm{I} 0$ & 4.580 & 2.177 \\
Incumbent advantage & $\mathrm{I}$ & 5 & 3.257 & 1.329 \\
Nonprofit & 0 & $\mathrm{I}$ & 0.266 & 0.443 \\
Other government & 0 & $\mathrm{I}$ & 0.092 & 0.289 \\
Trusted vendor & $\mathrm{I}$ & 5 & 3.786 & 1.083 \\
Reputation known & $\mathrm{I}$ & 5 & 3.938 & 1.016 \\
Community ties & $\mathrm{I}$ & 5 & 3.615 & 1.220 \\
Expectation of continuity & $\mathrm{I}$ & 5 & 3.976 & 1.012 \\
Professional manager & 0 & $\mathrm{I}$ & 0.740 & 0.439 \\
Suburban & 0 & $\mathrm{I}$ & 0.385 & 0.487 \\
Rural & 0 & $\mathrm{I}$ & 0.157 & 0.364 \\
Few vendors available & $\mathrm{I}$ & 5 & 3.509 & 1.369 \\
Political connections & $\mathrm{I}$ & 5 & 2.717 & 1.235 \\
County & 0 & $\mathrm{I}$ & $0.49 \mathrm{I}$ & 0.501 \\
Population & 0.026 & 9.519 & 0.220 & 0.764 \\
\hline
\end{tabular}

$\mathrm{b}_{9}$ Suburban $+\mathrm{b}_{10}$ Few vendors $+\mathrm{b}_{11}$ Contract features* + $\mathrm{b}_{12}$ Political connections $+\mathrm{b}_{13}$ County $+\mathrm{b}_{14}$ Population $+\mathrm{e}$.

* Only included in the Contacts and Coordination and Use of Discretion in Sanctioning models.

The above models imply triangular systems of equations. That is, the dependent variable from the first model, Contract features, is thought to affect the dependent variables in the subsequent equations (Contacts and coordination and Use of discretion in sanctioning) but not vice versa. Hausman tests indicate that the systems are recursive. ${ }^{5}$ Therefore, modeling them as three separate equations is appropriate. ${ }^{6}$

\section{Results}

In Table 4, we report the results of our three analyses into the determinants of the formal versus relational characteristics of contract governance structures. 


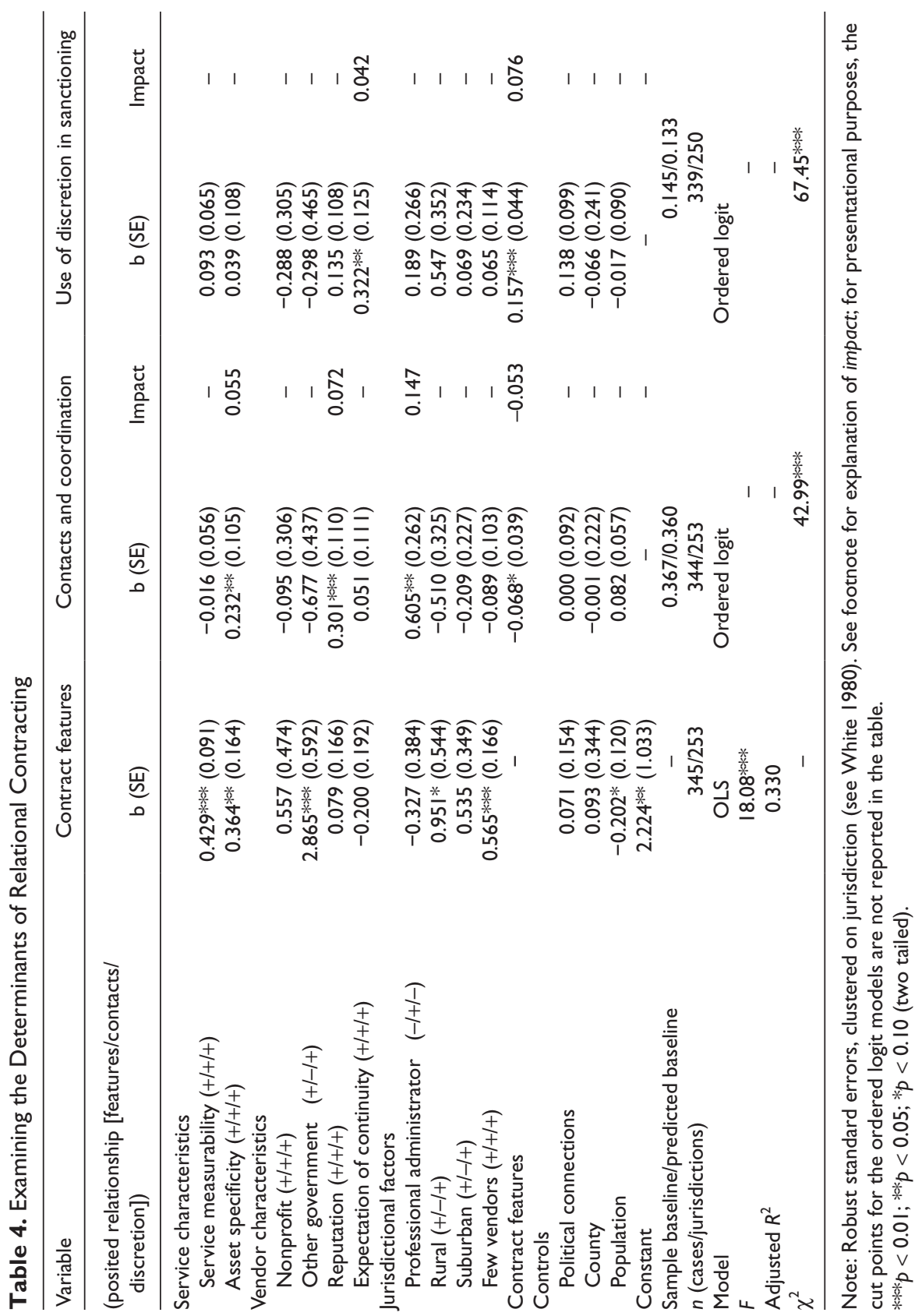


To ease interpretation, we have included the posited relationships in parentheses after each independent variable name. Turning first to the Contract Features model, one sees that service characteristics, vendor characteristics, and jurisdictional factors all play a role in determining how contracts are written.

Service characteristics seem especially important. Both Service measurability and Asset specificity are positively and significantly related to the written contract features, as posited, indicating that as services become harder to define, performance becomes more difficult to evaluate, and vendors become more challenging to replace because of concerns with asset specificity, contract writing becomes more relational in nature. Substantively speaking, Service measurability is notably more impactful, after accounting for its scale. ${ }^{7}$

The sector of the vendor also proves to be an important indicator of the formalness of contract terms. As hypothesized, when contracting with other governments, public managers tend to write more relational-style contracts than when they contract with for-profit vendors. Next to Service measurability, this is the most substantively impactful variable in the model. Contrary to expectations, however, contracts written for nonprofits do not appear to be more or less formal than those written for their profit-earning counterparts. Finally regarding sector, other governments are also distinguishable from nonprofits in terms of contract features - contracts with other governments score toward the higher end of the relational spectrum $\left(\mathrm{b}_{\text {Other government }}-\mathrm{b}_{\text {Nonprofit }}=2.308\right.$, $p=0.000) .{ }^{8}$ This would appear to lend support to the proposition that public managers show deference to contractors from the same sector (Lamothe and Lamothe 2010; Marvel and Marvel 2007).

The vendor's reputation and whether there is an expectation of an ongoing relationship do not appear to have independent influences on contract writing in terms of the formal-relational aspects of the contract. The idea that capacity is associated with contracting characteristics is also not well supported. Council-manager forms of government are not statistically related to the dependent variable, nor are suburbs more likely than urban areas to opt for relational terms. Only Rural achieves even a marginal level of significance. Substantively, this variable has the weakest effect of the statistically significant variables. Finally, the market environment does appear to play a role in defining contract terms The more limited the government perceives the vendor market to be, the more relationally contracts are written.

Fewer variables are related to the first management style variable, Contacts and coordination, and generally they are not the same ones that affected Contract features except for the asset-specific characteristics of services. 
From a substantive perspective, a 1-unit increase in this variable is associated with increasing the probability of Contacts and coordination scoring 5 by 5.5 percentage points (see the "Impact" column), which represents a 15.3\% increase over the baseline probability. ${ }^{9}$ This is one of the weaker associations in the model.

Vendor ownership does not seem to matter much, but the contractor's reputation appears to be influential in determining the extent of communication exchanged between governments and their service providers. Perhaps reputable vendors tend to be considered more as partner than agents and are treated as such. There is also some evidence that capacity leads to more frequent contacts and coordination especially in terms of whether the jurisdiction has a professional administrator. This is, in fact, the variable with the greatest substantive import in the Contacts and coordination model. The coefficients for Rural and Suburban are both in the posited direction, indicating that lack of capacity leads to less "hands-on" management; however neither reaches conventional levels of significance. Finally, the terms of the written contract are negatively related to the level of coordination occurring during contract execution. That is, more formally written contracts are more relationally managed, on this metric. This is an interesting result and supports our thesis that dual mechanisms are in place simultaneously. While public managers may feel the need to write contracts as formally as their service characteristics and the market environments allow, they are willing to coordinate with vendors more frequently than might be expected given the specificity of the written documents, especially when they have the capacity to do so and the vendors are perceived to be highly reputable.

Lastly, turning to the Use of Discretion in Sanctioning model, we see that the only variable, other than contract terms, that is significantly related to the dependent variable is Expectation of continuity. This finding indicates that when the relationship is expected to continue, public managers are hesitant to impose sanctions mechanistically and, rather, are more likely to opt for negotiation and compromise to correct deficient results. This variable is highly influential, with a 1-unit increase associated with a $31.6 \%$ increase in the likelihood of observing a 5 on the dependent variable, Use of discretion in sanctioning. ${ }^{10}$

As mentioned, Contract features is also significantly and positively related to the dependent variable, which suggests a close alignment rather than deviation between written contracts and management styles. This is a very impactful variable, even more so than Expectation of continuity. Unlike the coordination dimension, however, this finding does not support the mixed governance pattern evidenced in the Contacts and coordination model. 


\section{Discussion and Conclusion}

In this article, we test the proposition that local governments adopt mixed governance strategies by deploying both formal and relational mechanisms to formulate and manage service contracts. We also expect that contract writing and implementation are shaped differently by a set of service, vendor, and jurisdictional characteristics. Overall, we find support from the responding cities that formal and relational mechanisms coexist in contracting governance regimes.

The presence of mixed governance schemes is first evidenced by our factor analysis, which suggests a clear divergence between the three contract feature variables and the frequency of contact and coordination variable. Written contract features included as an independent variable in the Contacts and Coordination and Use of Discretion in Sanctioning models affirm our suspicion of local managers utilizing mixed governance, especially in terms of developing formal structures for contracts but managing them "hands on" at the same time. However, public managers seem to be more bound by the specificity laid out in written sanction clauses when implementing penalties.

Our results also offer some evidence of the different factors affecting written contract structures and management style. The findings from the three determinant models indicate that local governments seem to adhere to economic theory when writing contracts but tend to deviate from it when actually managing the contracts. That is, they write formalistic contracts when services are perceived to have low transaction costs and vendor service markets are robust; however, such considerations do not appear to be overly influential in determining how rarely or frequently they collaborate with their vendors during implementation and how strictly or loosely they invoke formal sanction mechanisms when noncompliance occurs. Rather, things like vendor reputation and the contracting government's management capacity come to the forefront regarding the frequency of contact. Whether local governments expect long-term relationships with their vendors seems to matter in determining how willing public managers are to negotiate instead of straightforwardly imposing sanctions.

There are several theoretical implications that can be drawn from our findings. First, the results of this study question the conventional dichotomous understanding of governance (i.e., formal versus relational) found in the past contracting literature and call for a better articulation of the governance schemes practiced by local public managers. Pragmatic-minded local managers appear to blend formal and relational strategies, instead of adhering to 
one or the other method, to pursue accountability and assertively manage contracts to the extent that their internal (e.g., management capacity) and external conditions (e.g., transaction cost nature of services) permit. A challenge for future research is to better ascertain under what circumstances different governance patterns emerge. Second, with relation to the challenging task of discovering such conditions, this study begins to identify various service, vendor, and jurisdictional determinants that either facilitate or restrain the formal or relational aspects of governance arrangements. This study also suggests that local governance is a multidimensional concept where the structure and management of contracts are not necessarily aligned and may be affected by different sets of factors. The complexity and multidimensional aspects of local governance should be better accounted for in future scholarly efforts. Furthermore, there is a need to better understand the dimensions of management style. As our findings indicate, levels of contacts and coordination appear to be weakly and negatively related to contract specificity while sanctioning discretion seems to be strongly and positively related. Further exploration is needed to clarify when contract terms effectively constrain management behavior and when they do not.

Our findings also highlight the need to further explore the communications that occur between contracting governments and their vendors during contract implementation. Our measure simply captures the extent to which such activities take place. Future research should seek to explore the varying nature of the communications and whether different types of services (such as hard vs. soft) and vendors (such as nonprofit, for-profit, and other government) are associated with different sorts of communications. A related question is whether higher levels of communication or certain types of communications/interactions are associated with better performance. The answer to these questions could have important implications for practitioners. If more contacts and coordination (possibly, of certain types) improve the efficacy of contracting and capacity is related to the volume of such interactions, this would be a strong argument that governments would be wise to invest in such resources.

We want to reiterate a final concern prior to closing. Our response rate and sample size are smaller than ideal. Further, jurisdictions with larger populations and those with council-manager forms of government are overrepresented. These factors could adversely impact the generalizability of our findings and call for future efforts to confirm or refute them through the use of larger, more representative samples. 


\section{Appendix A}

\section{List of Services Included in the Analyses}

\section{Hard Services}

Soft Services
- Residential solid waste collection

- Solid waste disposal

- Tree trimming and planting on public rights of way

- Street repair

- Animal control/shelter

- Operation of parking lots and garages

- Traffic sign/signal installation/ maintenance

- Commercial solid waste collection

- Street/parking lot cleaning

- Operation/maintenance of bus transit system

- Recycling

- Operation/maintenance of paratransit system

- Sewage collection and treatment

- Snow plowing/sanding

- Parking meter maintenance and collection

- Disposal of sludge

- Pest control

- Water treatment

- Inspection/code enforcementDisposal of hazardous materials

\section{Appendix B}

\section{Measures Used in the Analysis}

\section{Dependent variables}

Contract features An additive scale consisting of three 5-point ordinal indicators; thus the variable ranges from 3 to 15 (Cronbach's alpha $=0.749$ ), such that:

I. For the first variable, I indicates "contract is rebid regularly, regardless of incumbent performance" and 5 indicates "contract is not rebid unless incumbent discontinues service or has serious problems." 


\section{Appendix B (continued)}

2. For the second variable, I indicates "contract explicitly spells out deliverables, performance measures, and reporting requirements" and 5 indicates "contract does not cover detailed requirements, but contract terms and obligations are mutually understood."

3. For the third variable, I indicates "contract explicitly lays out sanction clauses that contain specific and detailed penalties" and 5 indicates "contract does not have explicit sanction clauses that detail penalties."

Contacts and coordination

Use of discretion in sanctioning
A 5-point ordinal scale with I indicating "contacts and coordination with the vendor are rare during contract implementation" and 5 indicating "contacts and coordination with the vendor are very common during contract implementation."

A 5-point ordinal scale with I indicating "sanctions are imposed as written in the contract with little discretion or negotiation" and 5 indicating "negotiation often takes place without formal sanctioning and contract terms may be altered as a result."

Independent variables

Service
measurability

Asset specificity

Ownership
An additive scale consisting of two 5-point ordinal indicators, thus the variable ranges from 2 to 10 (Cronbach's alpha $=$ 0.799), such that:

I. For the first variable, I indicates "tasks are standardized and easily defined" and 5 indicating "tasks require customization and are not easy to define."

2. For the second variable, I indicates "performance and service quality are easy to measure" and 5 indicating "performance is hard to measure and service quality is hard to determine."

A 5-point ordinal scale with I indicating "due to the nature of the service or the clients served, incumbents do not have an advantage over other vendors and are easy to replace" and 5 indicating "due to the nature of the service or specific needs of clients, incumbents have an advantage over other vendors and are difficult to replace."

Two dichotomous variables identifying vendor type:

I. "Nonprofit" scores I if the vendor is a nonprofit organization.

2. "Other government" scores I if the vendor is another government agency. Hence, the comparison category is for-profit vendors. 


\section{Appendix B (continued)}

\begin{tabular}{|c|c|}
\hline Reputation & $\begin{array}{l}\text { A 5-point ordinal scale with I indicating "reputation of the } \\
\text { vendor was not known prior to contracting and thus not } \\
\text { considered in vendor selection" and } 5 \text { indicating "reputation } \\
\text { of the vendor was well known prior to contracting and } \\
\text { served as a deciding factor in vendor selection." }\end{array}$ \\
\hline $\begin{array}{l}\text { Expectation of } \\
\text { continuity }\end{array}$ & $\begin{array}{l}\text { A 5-point ordinal scale with I indicating "it is very unlikely } \\
\text { that we will have a continuing relationship with this vendor } \\
\text { (including outside this contract)" and } 5 \text { indicating "it is highly } \\
\text { likely that we will have a continuing relationship with this } \\
\text { vendor (including outside this contract)." }\end{array}$ \\
\hline $\begin{array}{l}\text { Professional } \\
\text { administrator }\end{array}$ & $\begin{array}{l}\text { Dichotomous variable that scores I for council-manager } \\
\text { (cities) and council-administrator (counties) forms of } \\
\text { government. }\end{array}$ \\
\hline Metro status & $\begin{array}{l}\text { Two dichotomous variables identifying vendor type: } \\
\text { I. "Rural" scores I if the jurisdiction is classified as rural. } \\
\text { 2. "Suburban" scores I if the jurisdiction is classified as } \\
\text { suburban.Hence, the comparison category is urban } \\
\text { jurisdictions. }\end{array}$ \\
\hline Few vendors & $\begin{array}{l}\text { A } 5 \text {-point ordinal scale with I indicating "there are many } \\
\text { vendors available in the market to replace the incumbent" } \\
\text { and } 5 \text { indicating "there are very few vendors in the market to } \\
\text { replace the incumbent." }\end{array}$ \\
\hline
\end{tabular}

Control variables

$\begin{array}{ll}\begin{array}{l}\text { Political } \\ \text { connections }\end{array} & \begin{array}{l}\text { A 5-point ordinal scale with I indicating "this vendor has } \\ \text { essentially no political connections" and } 5 \text { indicating "this } \\ \text { vendor is politically very well connected." }\end{array} \\ \text { County } & \text { A dichotomous variable scoring I if the jurisdiction is a county } \\ \text { Population } & 2000 \text { U.S. census population in millions (transformed to millions } \\ & \text { so variable scales are compatible). }\end{array}$

Note: The 5-point scales referenced above represent the actual questions posed to the respondents. For each service for which they responded, they were asked to mark on a number line what they felt to be the appropriate answer ranging between the "I" and " 5 " options listed above. 


\section{Appendix C}

Comparison of Characteristics of the Municipalities in the Sample with the U.S., Overall ICMA List, and Requested ICMA List. $^{a}$

\begin{tabular}{|c|c|c|c|c|}
\hline Characteristic & $\begin{array}{l}\text { United } \\
\text { States, \% }\end{array}$ & $\begin{array}{l}\text { ICMA List } \\
\text { (Overall), \% }\end{array}$ & $\begin{array}{c}\text { ICMA List } \\
\text { (Requested), \% }\end{array}$ & Sample, \% \\
\hline \multicolumn{5}{|l|}{ Population } \\
\hline Less than 10,000 & $86.6^{a}$ & 54.7 & 0.0 & 0.0 \\
\hline $10,000-49,999$ & 10.4 & 36.2 & 28.1 & 21.1 \\
\hline $50,000-249,999$ & 2.6 & 8.2 & 64.5 & 73.4 \\
\hline 250,000 or greater & 0.3 & 0.9 & 7.4 & 5.5 \\
\hline \multicolumn{5}{|l|}{ Region } \\
\hline Northeast & $13.2^{b}$ & $21 . I^{c}$ & 19.6 & 12.5 \\
\hline North-central & 32.5 & 30.8 & 24.6 & 21.1 \\
\hline South & 35.8 & 33.5 & 25.1 & 31.3 \\
\hline West & 18.5 & 14.7 & 30.7 & 35.2 \\
\hline \multicolumn{5}{|l|}{ Metro status } \\
\hline Central & NA & NA & 43.7 & 36.7 \\
\hline Suburban & NA & NA & 51.4 & 58.6 \\
\hline Independent & NA & NA & 5.0 & 4.7 \\
\hline \multicolumn{5}{|l|}{ Form of government } \\
\hline Mayor-council & NA & NA & 34.7 & 17.2 \\
\hline Council-manager & NA & NA & 62.6 & 82.0 \\
\hline Commission & NA & NA & 1.6 & 0.8 \\
\hline Town meeting & $\begin{array}{c}\text { NA } \\
(n=35,933)\end{array}$ & $\begin{array}{c}\text { NA } \\
(n=7,231)\end{array}$ & $\begin{array}{c}\mathrm{I} . \mathrm{I} \\
(\mathrm{n}=925)\end{array}$ & $\begin{array}{c}0.0 \\
(n=128)\end{array}$ \\
\hline
\end{tabular}

Note: NA, not available.

${ }^{a}$ Information on U.S. jurisdictions were available only for municipalities and not counties. Therefore, we dropped counties from our comparison. The municipality/county breakdown for each of the categories is as follows: United States, 35,933/3034 (U.S. Census Bureau 2002); ICMA List (Overall), 7,23 I/3039 (ICMA's academic researcher's order form, available from ICMA); ICMA list (Requested), 925/I075 (authors' calculations); Sample, I28/I26 (authors' calculations).

bESRI (2003).

'The ICMA order sheet did not break down region by municipalities and counties, so the numbers reported here are for the aggregate.

\section{Declaration of Conflicting Interests}

The author(s) declared no potential conflicts of interest with respect to the research, authorship, and/or publication of this article. 


\section{Funding}

The author(s) received no financial support for the research, authorship, and/or publication of this article.

\section{Notes}

1. Respondents were asked to record their answers for the 5-point scale questions by marking a number line with values running from 1 to 5 . This allowed some to choose midrange values, such as 3.5 . Such choices were not overly common and only accounted for about $3 \%$ of responses for the questions included in the analysis. Also, the only midrange options marked were midpoints. Therefore, our 5-point scales actually contain up to nine ordered response categories.

2. Our response rate is lower than we would like, but as illustrated above, every effort was made to increase it. We suspect our survey was, to some extent, a victim of the current economic climate in which local governments are dealing with unprecedented budget shortfalls leading to difficulty in maintaining staffing levels, among other issues, that might make it more difficult/unlikely they would have the resources or be willing to make an effort to fill out our survey. It is also worth mentioning that recent research into survey methods generally find lack of consistent relationships between low response rates and response bias (Groves 2006) and, in the random-digit-dial (RDD) context, Keeter et al. $(2006,766)$ find "that achieving a higher response rate does not yield significantly different estimates for the vast majority of questions." While this finding is not directly applicable to the current study, as we use a mail survey, there seems no obvious reason why tendencies toward bias should vary between the different methodologies.

3. It should be noted that while we have no definitive information on the distribution of forms of governments in the United States, the requested ICMA list likely also has a disproportionately large number of council-manager jurisdictions. For example, ICMA's most recent municipal (2006) and county (2007) form of government surveys found $54.5 \%$ and $46.0 \%$ council-manager governments, respectively, as opposed to the $62.6 \%$ in the requested list. Overviews of both surveys can be downloaded from http://icma.org/en/results/surveying/ survey_research/survey_results (accessed April 15, 2011).

4. Like our other 5-point measures, some respondents marked half-points on the Contacts and coordination and Use of discretion in sanctioning variables (10 cases, $2.9 \%$, for each variable). This is not problematic for the independent variables, but it does pose an issue for dependent variables. While OLS seems appropriate for 9-point scales, it does not seem so in this instance owing to the paucity of half-point responses. We decided to go with ordered logit models instead. To do so, we rounded the half-points up and estimated the models, rounded down and estimated, and dropped the half-point responses and estimated. 
This allowed us to compare the results for the various configurations. The results, reported in Table 4, are from the "round up" models. Across the models, the only differences were that Other government and Population both moved to marginal levels of significance ( $p=0.090$ and 0.093 , respectively) in the round down version of the Contracts and Coordination model and Measurability moved to marginal significance $(p=0.097)$ in the drop version of the Use of Discretion in Sanctioning model. Interested readers can contact the authors for more information on the sensitivity analyses.

5. Hausman tests were conducted using the "ivendog" command in Stata. For both the Contacts and Coordination and Use of Discretion in Sanctioning models, the null hypothesis that Contract features is exogenous could not be rejected ( $p=0.452$ and $p=0.495$, respectively).

6. In addition to running the models separately, we also ran a path analysis, although this is not technically an appropriate model since both of the management style dependent variables are ordered (Garson 2008). The results were generally in line with those presented in Table 4, with the exceptions that there was evidence that Population might have an indirect effect on Contracts and coordination through its relationship with Contract features and Measurability appears to have an indirect effect on Use of discretion in sanctioning. Interested readers may contact the authors for further information in this regard.

7. That is, moving from its lowest score (2) to its highest score (10), it is associated with increasing the dependent variable 3.4 units. Since Contract features has a range of 12 (i.e., from 3 to 15), this means that maximum movement on Service measurability accounts for about $28.6 \%$ of the range of the dependent variable. On the other hand, Asset specificity ranges from 1 to 5 . So, max movement on this variable translates to a 1.5 unit increase in the dependent variable which represents $12.5 \%$ of Contract features's range.

8. The standard error for the hypothesis test of the difference between the coefficient estimates was calculated as: $\mathrm{se}_{\text {OTHERGOVT-NP }}=\sqrt{v a r_{\text {OTHERGOVT }}+v a r_{\mathrm{NP}}-2 \operatorname{cov} v_{\text {OTHERGOVT,NP }}}$

9. "Impact" is constructed by first setting all dichotomous variables at zero, all 5 -point ordered variables at 4 , and continuous variables at their means. The baseline predicted probabilities for the five categories of the dependent variable are calculated from these settings. Doing so produces predicted probabilities of scoring 5 of 0.360 for Contacts and coordination and 0.133 for Use of discretion in sanctioning. These compare favorably with the actual probabilities of such scores in the data set, which are 0.367 and 0.145 , respectively. Next, in turn, the value associated with each statistically significant variable is increased by 1 (continuous variables by 1 standard deviation) and new probabilities are computed. "Impact" is calculated by the equation: $P(5)_{\text {new }}-P(5)_{\text {baseline }}$ for each 
variable, and represents the change in the probability of the dependent variable scoring 5 .

10. Since the baseline probability of scoring 5 on the dependent variable is $13.3 \%$, a 4.2 percentage point increase represents a $31.6 \%$ increase.

\section{References}

Adler P. 2001. Market, hierarchy, and trust: The knowledge economy and the future of capitalism. Organization Science 12 (2): 214-34.

Amirkhanyan, Anna. 2009. Collaborative performance measurement: Examining and explaining the relevance of collaboration in state and local government contracts. Journal of Public Administration Research and Theory 19 (3): 523-54.

Axelrod, Robert M. 1984. The evolution of cooperation. New York: Basic Books.

Beinecke, Richard H., and Robert DeFillippi. 1999. The value of the relationship model of contracting in social services reprocurements and transitions: Lessons from Massachusetts. Public Productivity and Management Review 22 (4): 490-501.

Bernheim, B. Douglas, and Michael D. Whinston. 1998. Incomplete contracts and strategic ambiguity. American Economic Review 88 (4):902-32.

Brown, Trevor L., and Matthew Potoski. 2003a. Transaction costs and institutional explanations for government service production decisions. Journal of Public Administration Research and Theory 13 (4): 441-68.

Brown, Trevor L., and Matthew Potoski. 2003b. Contract-management capacity in municipal and county governments. Public Administration Review 63 (2): 153-64.

Brown, Trevor L., and Matthew Potoski. 2005. Transaction costs and contracting: The practitioner perspective. Public Performance \& Management Review 28 (3): 326-51.

Carson, Stephen J., Anoop Madhok, and Tao Wu. 2006. Uncertainty, opportunism, and governance: The effects of volatility and ambiguity on formal and relational contracting. Academy of Management Journal 49 (5): 1058-77.

DeHoog, Ruth Hoogland. 1990. Competition, negotiation, or cooperation: Three models for service contracting. Administration and Society 22 (3):317-40.

Domberger, Simon, and Paul Jensen. 1997. Contracting out by the public sector: Theory, evidence, prospects (Contracting out in the United Kingdom and elsewhere). Oxford Review of Economic Policy13 (4):67-78.

ESRI. 2003. ESRI data \& maps [DVD]. Redlands, CA: ESRI.

Ferris, James, and Elizabeth Graddy. 1986. Contracting out: For What? With whom? Public Administration Review 46 (4): 332-44.

Ferris, James, and Elizabeth Graddy. 1991. Production costs, transaction costs, and local government contractor choice. Economic Inquiry 29 (3): 541-54.

Frumkin, Peter. 2002. On being nonprofit: A conceptual and policy primer. Cambridge, MA: Harvard University Press. 
Garson, G. David. 2008. Path Analysis. From Statnotes: Topics in Multivariate Analysis. http://faculty.chass.ncsu.edu/garson/pa765/statnote.htm (accessed 2/15/11).

Ghoshal, Sumantra, and Peter Moran. 1996. Bad for practice: A critique of the transaction cost theory. Academy of Management Review 21 (1): 13-47.

Goo, Jahyun, Rajiv Kishore, H. R. Rao, and Kichan Nam. 2009. The role of service level agreements in relational management of information technology outsourcing: An empirical study. MIS Quarterly 33 (1): 119-45.

Greene, Jeffrey D. 1996. Cities and privatization: Examining the effect of fiscal stress, location, and wealth in medium-sized cities. Policy Studies Journal 24 (1): 135-44.

Groves, Robert M. 2006. Nonresponse rates and nonresponse bias in household surveys. Public Opinion Quarterly 70 (5): 646-75.

Gulati, Ranjay. 1995. Does familiarity breed trust? The implications of repeated ties for contractual choice in alliances. Academy of Management Journal 38 (1): 85-112.

Hansmann, Henry. 1987. Economic theories of nonprofit organization. In The nonprofit sector: A research handbook, ed. Walter Powell. New Haven, CT: Yale University Press.

Hefetz, Amir, and Mildred Warner. 2004. Privatization and its reverse: Explaining the dynamics of the government contracting process. Journal of Public Administration Research and Theory 14 (2):171-90.

Hill, Charles W. L. 1990. Cooperation, opportunism, and the invisible hand: Implications for transaction cost theory. Academy of Management Review 15 (3): 500-13.

Hirsch, Werner Z. 1991. Privatizing government services: An economic analysis of contracting out by local governments. Los Angeles: Institute of Industrial Relations Publication Center, University of California, Los Angeles.

Honadle, Beth Walter. 2001. Theoretical and practical issues of local government capacity in an era of devolution. Journal of Regional Analysis and Policy 31 (1): 77-90.

Jang, HeeSoun. 2006. Contracting out parks and recreation services: Correcting for selection bias using a Heckman selection model. International Journal of Public Administration 29 (10): 799-818.

Jensen, Michael C., and William H. Meckling. 1976. Theory of the firm: Managerial behavior, agency costs and ownership. Journal of Financial Economics 3 (4): 305-60.

Keeter, Scott, Courtney Kennedy, Michael Dimock, Jonathan Best, and Peyton Craighill. 2006. Gauging the impact of growing nonresponse on estimates from a national RDD survey. Public Opinion Quarterly 70 (5): 759-79.

Kodrzycki, Yolanda K. 1998. Fiscal pressure and the privatization of local services. New England Economic Review (Jan/Feb): 39-50. 
Lamothe, Meeyoung, and Scott Lamothe. 2010. Competing for what? Linking competition to performance in social service contracting. American Review of Public Administration 40 (3): 326-50.

Lamothe, Scott, Meeyoung Lamothe, and Richard C. Feiock. 2008. Examining local government service delivery arrangements over time. Urban Affairs Review 44 (1): 27-57.

Larson, Andrea. 1992. Network dyads in entrepreneurial settings: A study of the governance of exchange relationships. Administrative Science Quarterly 37 (1):76-104.

Lee, Yikuan, and S. Tamer Cavusgil. 2006. Enhancing alliance performance: The effects of contractual-based versus relational-based governance. Journal of Business Research 59 (8): 896-905.

Levin, Jonathan, and Steven Tadelis. 2010. Contracting for government services: Theory and evidence from U.S. cities. Journal of Industrial Economics 58 (3): 507-41.

Macneil, Ian R. 1978. Contracts: Adjustments of longer-term economic relations under classical, neoclassical, and relational contract law. Northwestern University Law Review 72 (6): 854-905.

Marvel, Mary K., and Howard P. Marvel. 2007. Outsourcing oversight: A comparison of monitoring for in-house and contracted services. Public Administration Review 67 (3): 521-30.

Marvel, Mary K., and Howard P. Marvel. 2009. Shaping the provision of outsourced public services: Incentive efficacy and service delivery. Public Performance and Management Review 33(2): 183-213.

Milgrom, Paul, and John Roberts. 1988. Theories of the firm: Past, present, and future. Canadian Journal of Economics 21 (3): 444-58.

Milward, Brinton H., and Keith G. Provan. 2000. Governing the hollow state. Journal of Public Administration Research and Theory 10 (2): 359-79.

Mohr, Robert, Steven C. Deller, and John M. Halstead. 2010. Alternative methods of service delivery in small and rural municipalities. Public Administration Review 70 (6): 894-905.

Ouchi, William G. 1980. Markets, bureaucracies, and clans. Administrative Science Quarterly 25 (1): 129-41.

Poppo, Laura, and Todd Zenger. 2002. Do formal contracts and relational governance function as substitutes or complements? Strategic Management Journal 23 (8): 707-25.

Poppo, Laura, Kevin Zheng Zhou, and Sungmin Ryu. 2008. Alternative origins to interorganizational trust: An interdependence perspective on the shadow of the past and the shadow of the future. Organization Science 19 (1): 39-55.

Ring, Peter Smith, and Andrew H. Van de Ven. 1992. Structuring cooperative relationships between organizations. Strategic Management Journal 13 (7): 483-98. 
Romzek, Barbara, and Jocelyn Johnston. 2002. Effective contract implementation and management: A preliminary model. Journal of Public Administration Research and Theory 12 (3):423-53.

Salamon, Lester M. 1995. Partners in public service: Government-nonprofit relations in the modern welfare state. Baltimore, MD: Johns Hopkins University Press.

Sclar, Elliot. 2000. You don't always get what you pay for: The economics of privatization. Ithaca, NY: Cornell Univ. Press.

Smith, Steven Rathgeb, and Michael Lipsky. 1993. Nonprofit for hire: The welfare state in the age of contracting. Cambridge, MA: Harvard Univ. Press.

Stein, Robert M. 1993. Arranging city services. Journal of Public Administration Research and Theory 3 (1): 66-92.

U.S. Census Bureau. 2002. Census of governments: Volume 1, number 1, Government Organization, GCO2(1)-1. Washington, DC: U.S. Government Printing Office.

Uzzi, Brian. 1997. Social structure and competition in interfirm networks: The paradox of embeddedness. Administrative Science Quarterly 42 (1): 35-67.

Van Slyke, David M. 2007. Agents or stewards: Using theory to understand the government-nonprofit social service contracting relationship. Journal of Public Administration Research and Theory 17 (2): 157-87.

Vandaele, Darline, Deva Rangarajan, Paul Gemmel, and Annouk Lievens. 2007. How to govern business services exchanges: Contractual and relational issues. International Journal of Management Reviews 9 (3): 237-58.

Weisbrod, Burton A. 1977. The voluntary non-profit sector: An economic analysis. Lexington, MA: Lexington Books.

White, Halbert. 1980. A heteroscedasticity-consistent covariance matrix and a direct test for heteroscedasticity. Exonometrica 48 (4): 817-38.

Williamson, Oliver E. 1985. The economic institutions of capitalism. New York: The Free Press.

Williamson, Oliver E. 1991. Comparative economic organization: The analysis of discrete structural alternatives. Administrative Sciences Quarterly 36 (2): 269-96.

\section{Bios}

Meeyoung Lamothe is currently an assistant professor at the University of Oklahoma. Her research interests include local alternative service delivery arrangements, social service contracting, and nonprofit management. Her recent publications may be found in the Journal of Public Administration Research and Theory, International Journal of Public Administration, and American Review of Public Administration.

Scott Lamothe is an assistant professor in the department of political science at the University of Oklahoma. His current research focuses on contracting decisions and the role of competition. His recent work has been published in the Journal of Public Administration Research and Theory, American Review of Public Administration, and Urban Affairs Review. 